\title{
CARCINOMA ESPINOCELULAR DE PELE COM METÁSTASE LINFONODAL: RELATO DE CASO E REVISÃO DE LITERATURA
}

\author{
Ramille Gonçalves Oliveira ${ }^{1}$; Jadivan Leite de Oliveira ${ }^{2}$; Márcio Lima Leal Arnaut Junior ${ }^{3}$; \\ Gabriel Pereira Bernardo ${ }^{1}$; Emanuel Severiano Feitosa ${ }^{1}$
}

Introdução: $O$ câncer de pele não melanoma (CPNM) vem aumentando sua incidência nas últimas décadas no Brasil e no mundo. O CPNM pode ser dividido em duas principais entidades, o carcinoma basocelular (CBC), mais comum responsável por $75 \%$ das neoplasias e o carcinoma espinocelular (CEC), que compreende $20 \%$ dos casos. O CEC origina-se da camada escamosa da epiderme e tem na mutação do gene p53 sua principal base molecular. Este tumor pode se desenvolver em qualquer área da pele exposta ao sol, pois tem na radiação ultravioleta (UV) seu principal fator etiológico. Outros fatores de risco importantes são: pele, olhos e cabelos claros, imunossupressão, exposição a agentes químicos, infecção pelo Papilomavirus Humano (HPV), úlceras crônicas, queimaduras e tabagismo. O diagnóstico de suspeita pode ser feito clinicamente e confirmado por histopatológico. A chance de metástase linfonodal e hematogênica do CEC é baixa. Objetivo: Mostrar a importância do diagnóstico correto, do estadiamento e tratamento cirúrgico de um paciente com CEC moderadamente diferenciado de pele e metástase linfonodal. Relato de Caso: I.S.O, 62 anos, masculino, tabagista e etilista diário, com lesão em região supraclavicular esquerda em crescimento progressivo há 2 anos. Ao exame físico apresentava lesão ulcerada em região supraclavicular esquerda de 8,0 x $6,0 \mathrm{~cm}$ e linfonodomegalia axilar esquerda de 5,0 x 4,0 cm. Submetido a biópsia incisional da lesão com diagnóstico de CEC moderadamente diferenciado. Fez punção aspirativa com agulha fina (PAAF) da linfonodomegalia que foi positivo para células malignas. Realizou exames de estadiamento que não demonstraram lesão à distância. Foi submetido à ressecção ampla da lesão primária da fossa supraclavicular, linfadenectomia axilar nível I, II e III e reconstrução cirúrgica com retalho miocutâneo do músculo peitoral maior esquerdo. Laudo histopatológico: CEC moderadamente diferenciado medindo $8,0 \times 6,0 \times 0,6 \mathrm{~cm}$ infiltrando musculatura esquelética. Limites cirúrgicos livres. Na avaliação do produto da linfadenectomia axilar apresentava CEC metastático para 5 linfonodos dentre 8 linfonodos examinados. Estadiamento patológico pT3pN2. Conclusão: O diagnóstico precoce e o tratamento adequado para o CEC depende de fatores como o risco de recorrência e a presença ou não de metástase locorregional e a distância. A ressecção cirúrgica é o tratamento padrão-ouro para o CPNM. A linfadenectomia é realizada quando apresenta metástase linfonodal.

Palavras-Chave: carcinoma espinocelular, tratamento, linfadenectomia.

\footnotetext{
${ }^{1}$ Faculdade de Medicina Estácio de Juazeiro do Norte, Juazeiro do Norte, CE;

${ }^{2}$ Cirurgião Oncológico, INCA - Instituto Nacional do Câncer, Rio de Janeiro, RJ;

${ }^{3}$ Cirurgião Plástico, INCA - Instituto Nacional do Câncer, Rio de Janeiro, RJ.

Autor Correspondente: ramille.goncalves@ hotmail.com
} 